\title{
How I Treat Sarcomas during COVID-19 Pandemic: Caught Between the Devil and the Deep Sea!
}

Since its origin in the Wuhan province of China in December 2019, the COVID-19 pandemic has wreaked havoc across the world, infecting 1.5 million people to date and taking the lives of nearly 90,000 people. ${ }^{[1,2]}$ However, cancer is also a deadly disease, estimated to affect 18 million people in 2020. ${ }^{[3]}$ There is not enough data yet to evaluate the effect of COVID-19 on cancer outcomes. The available limited data with cancer patients infected with COVID from China suggests that cancer patients may have greater morbidity and mortality. ${ }^{[4]}$ This data is not sufficient to make definite conclusions regarding cancer care, as each country and cancer center faces distinct challenges. This leaves the oncologist caught between the devil and the deep sea; weighing the benefits of cancer treatment against the risk of COVID-19 infection for each case. ${ }^{[5]}$ Patients may have to travel long distances to avail of oncological services especially in India. ${ }^{[6]}$ This may lead to more risk of exposure to COVID and a delayed presentation of cancer due to travel restrictions. Other indirect effects of COVID-19 may include a shortage of supportive care resources and drugs due to allocation and prioritization for COVID care. Hence, though multiple guidelines have been issued by different organizations, oncologists should be prepared to adapt the guidelines suitable for specific situations. ${ }^{[7-15]}$

Whenever the oncologist deviates from the standard treatment, patients should be counseled enough to understand the rationale behind the modifications and concur with the plan knowing that oncologic outcomes may be compromised. There should be clear documentation to avoid future medico-legal issues. All the patients may need good psychosocial support during these tough times; oncologists should endeavor to provide such support. ${ }^{[13,15]}$

The management of bone and soft-tissue sarcomas (STS) becomes more difficult due to the heterogeneous nature of this subset and intensive and long treatment protocols involving multidisciplinary treatment (MDT).

After the completion of preliminary investigations, preferably from the local, authentic laboratories, MDTs can be conducted by the available teleconferencing options. MDT discussions should include and document intent of treatment, treatment modifications planned based on the priority of treatment, and a treatment calendar; specifying the probable timing of surgery and radiotherapy. Furthermore, patients deemed to be at risk for COVID associated morbidity should be flagged; more caution from the patient and the onco-care team is warranted for such patients. There should be judicious planning to optimize care depending on host factors (performance status [PS] and comorbid conditions), tumor factors (pace of the disease), and infrastructure limitations. ${ }^{[7,8,10,15]}$

For most sarcomas, surgery is the mainstay of treatment. Unfortunately, the need for hospital admission, lack of adequate personal protective equipment (PPE), shortage of personnel, and logistic issues due to diversion of ventilators/ intensive care unit beds for COVID-19 patients have forced surgical oncologists also to reorganize their practices. ${ }^{[16,17]}$ Although oncologic surgeries are considered as a high priority, further ranking the surgeries into high, medium, and low priority based on patient condition and urgency of treatment, the magnitude of benefit in terms of overall survival (OS) or quality of life improvement and possible impact on the outcome by the delay of procedure may help the clinicians to manage the patients; as suggested by the ESMO guidelines. ${ }^{[8,18]}$ Like systemic therapy, surgeries also need to be considered on an individual basis. The various options to postpone surgery include the preferential use of neoadjuvant radiotherapy or chemotherapy in appropriate cases, careful active observation for slow-growing tumors, treating only those patients who have life-threatening conditions, or who are expected to have good outcomes in recurrent cases. ${ }^{[16,19]}$ Limiting the aerosol-generating procedures and shifting the elective surgical theatres away from the emergency services may help in infection control. ${ }^{[16,19]}$ Although the current Indian Council of Medical Research guidelines do not recommend routine testing of asymptomatic pre-surgical patients before surgery, there are many reports of hospitals performing such tests for ensuring the safety of the health-care team and other patients. ${ }^{[20-22]}$

Radiotherapy also requires to be planned carefully, adapting to the resource constraints. ${ }^{[23]}$

For all patients, the option of de-escalation of therapy has to be considered though there may be cases where the standard treatment may be delivered if the oncologist is confident of continued infrastructural support and stable COVID situation in fit patients with expected good outcomes. De-escalation would involve reducing the frequency of chemotherapy cycles, oral therapy like oral metronomic chemotherapy (OMCT) for palliative treatment, reducing the complications by using granulocyte colony-stimulating factors (G-CSF) (preferably Pegylated) with all the cycles of therapy and correction of nutritional deficiencies. For the subsequent cycles, dose modifications based on the prior toxicities should be carried out. ${ }^{[8,13,15]}$

Patients should preferably get temporary lodging facilities close to the hospital to reduce the risk of infection. The 
availability of blood donors should be ensured before starting treatment; however, transfusions should be minimized. Each center should make provisions for the patient to reach out to the doctor/nurse for tackling minor problems such as nausea, vomiting, and malaise, by social media support groups or telephonic support. ${ }^{[11-13]}$ However, it should also be emphasized that major problems such as fever or severe diarrhea or vomiting could be lifethreatening if the patient delays appropriate medical care. The fear of COVID exposure should not deter necessary hospital visits. However, the patient may be encouraged to visit nearby hospitals in emergencies to get appropriate, timely treatment.

Chemotherapy may be delivered in well-ventilated daycare units with strict compliance with the infection control guidelines. ${ }^{[13]}$ In select cases, intensive/longer chemotherapy protocols may be considered as inpatient treatment due to transport limitations; however, one must be cautious about iatrogenic infection and infrastructure limitations.

For elderly patients with comorbidities and poor ECOG PS in metastatic setting, OMCT with a combination of oral cyclophosphamide (50 mg OD), etoposide (50 mg OD), both daily for 21 days in a 28 days cycle ( 7 days off) and tamoxifen (20 mg BD) daily continuously may be used in Ewing sarcoma (ES) and STS. ${ }^{[2,25]}$ This OMCT may be considered in the curative setting as maintenance to bridge the gap when we are not administering IV chemotherapy or awaiting surgery. In osteosarcoma (OGS), cyclophosphamide $50 \mathrm{mg}$ daily for 21 days in a 28 days cycle and methotrexate (MTX) $12.5 \mathrm{mg}$ orally once in a week or oral sorafenib may be tried. ${ }^{[26,27]}$

Appropriate prognostication of each patient is essential in ES. ${ }^{[28-30]}$ For patients with localized disease, doses, and frequency of chemotherapy may be adjusted. If high-dose chemotherapy with stem cell rescue is planned, it may be postponed till the control of the COVID pandemic. ${ }^{[10]}$

In non-metastatic OGS, high-dose MTX based or ifosfamide based three-drug protocols like the OGS-12; are the standard chemotherapy options. ${ }^{[31-34]}$ Although we know that compliance with the standard drug therapy is associated with improved outcomes, two-drug regimens with Adriamycin/cisplatinum with decreased dosing intervals and G-CSF support may be adopted after discussing with the patient to lessen chances of neutropenia and increased susceptibility to COVID or other infections. ${ }^{[15,35]}$

STS includes chemosensitive, chemoresistant, and intermediate subtypes. Other risk factors for recurrence such as size, depth of the tumor, and the site of the disease, may also help to compute the benefit of adjuvant chemotherapy. ${ }^{[36,37]}$ While avoiding chemotherapy may be feasible for the poor chemosensitive and small volume subgroups, dose intensity and intervals may be appropriately modified in patients in chemosensitive histologies with large-volume disease, especially in young and good ECOG PS who qualify for adjuvant or neoadjuvant (NACT) therapy. In some cases, due to the unavailability of surgical services, NACT may have to be considered even for nonstandard indications. In such cases, specific patient consent should be documented. In metastatic or recurrent cases, OMCT or pazopanib may be preferred.

The treatment of fibromatosis may be modified and postponed. For patients on treatment with weekly MTX and vinblastine with continuous tamoxifen, tamoxifen can be continued while withholding vinblastine and MTX. Furthermore, imaging and reassessment maybe also avoided unless deemed necessary. ${ }^{[38]}$

Although less common in India, melanoma patients also need special care during this pandemic. ${ }^{[3]}$ In metastatic disease, the disease burden needs to be taken into account. In patients with the controlled disease, therapy may be temporarily stopped, after discussing with the patient. However, in other patients, immunotherapy protocols may be modified so that the least frequent dose is adopted; 4- or 6-weekly doses may be used, instead of 2- or 3-weekly. Single-agent checkpoint inhibitors are preferred over the combinations. ${ }^{[39]}$ Delayed identification of immune-related adverse events may lead to worse outcomes; hence, patients should be counseled well. Steroid use may worsen COVID susceptibility and complications, and hence, it should be used with caution. ${ }^{[39]}$

Oral options like temozolomide may be considered in patients, in whom IV chemotherapy is planned. ${ }^{[39]}$ Targeted therapy may be used in BRAF mutated melanoma.

The use of adjuvant treatment is to be decided on a case to case basis depending on the date of surgery and the risk of disease relapse. ${ }^{[39]}$

The government guidelines regarding travel and medical care are updated regularly as per the COVID situation. ${ }^{[40]}$ Hence, it is best to have a dynamic hospital policy for general patient management during this time. Furthermore, we need to process the huge amounts of data now emerging from the different parts of the world and integrate the applicable data to our clinical practice to improve outcomes of our patients, at the same time not compromising on the personal safety of our oncology team. Complete PPE includes goggles, face-shield, mask, gloves, coverall/ gowns, headcover, and shoe cover. For OPDs, an N95 mask and gloves are recommended. ${ }^{[41]}$ Unfortunately, there is a shortage of PPE in several hospitals, which also raises ethical issues for treating doctors ${ }^{[42]}$ While personal safety remains an individual priority, it is also important from a community point of view as an infected doctor is likely to infect many more persons than the other infected patients. Individualized case prioritization with MDT concurrence, region-specific appropriate modifications of systemic therapy and local therapy (surgery and radiotherapy) taking 
care not to overburden the logistics, and above all, personal and patient safety are the cornerstones for the management of patients during this difficult time.

Financial support and sponsorship

Nil.

\section{Conflicts of interest}

There are no conflicts of interest.

\section{Sharada Mailankody ${ }^{1}$, Jyoti Bajpai ${ }^{2}$}

${ }^{\prime}$ Department of Medical Oncology, Manipal Academy of Higher Education, Kasturba Medical College, Manipal, Karnataka, India, ${ }^{2}$ Department of Medical Oncology, Tata Memorial Center, Homi Bhabha National Institute, Mumbai, Maharashtra, India

Address for correspondence: Dr. Jyoti Bajpai, Department of Medical Oncology, Tata Memorial Center, Homi Bhabha National Institute, Room 1115, $11^{\text {th }}$ Floor, Homi Bhabha Block, Parel, Mumbai - 400 012, Maharashtra, India.E-mail: drjyotibajpai25@gmail. com,dr_jyotibajpai@yahoo.co.in

Submitted: 11-Apr-2020

Revised: 26-May-2020

Accepted: 29-May-2020

Published: 27-Jun-2020

\section{References}

1. Chen N, Zhou M, Dong X, Qu J, Gong F, Han Y, et al. Epidemiological and clinical characteristics of 99 cases of 2019 novel coronavirus pneumonia in Wuhan, China: A descriptive study. Lancet 2020;395:507-13.

2. Worldometer. Available from: https://www.worldometers.info/ coronavirus/? [Last accessed on 2020 Apr 09].

3. GLOBOCAN 2018. Available from: https://gco.iarc.fr/tomorrow/ home. [Last accessed on 2020 Apr 09].

4. Liang W, Guan W, Chen R, Wang W, Li J, Xu K, et al. Cancer patients in SARS-CoV-2 infection: A nationwide analysis in China. Lancet Oncol 2020;21:335-7.

5. Lewis MA. Between Scylla and Charybdis - Oncologic Decision Making in the Time of Covid-19. N Engl J Med. 2020;10.1056/ NEJMp2006588.

6. Sengar M, Fundytus A, Hopman WM, Malhotra H, Gupta S, Pramesh CS, et al. Medical oncology in India: Workload, infrastructure, and delivery of care. Indian J Med Paediatr Oncol 2019;40:121-7.

7. COVID-19 Rapid Guideline: Delivery of Systemic Anticancer Treatments. Available from: https://www.nice.org.uk/guidance/ ng161. [Last accessed on 2020 Apr 01].

8. NHS England's Clinical Guide for the Management of Cancer Patients during the Coronavirus Pandemic. Available from: https://www.england.nhs.uk/coronavirus/wp-content/uploads/ sites/52/2020/03/specialty-guide-acute-treatment-cancer-23march-2020.pdf. [Last accessed on 2020 May 27].

9. You B, Ravaud A, Canivet A, Ganem G, Giraud P, Guimbaud R, et al. The official French guidelines to protect patients with cancer against SARS-CoV-2 infection. Lancet Oncol 2020;21:619-21.

10. Shankar A, Saini D, Roy S, Mosavi Jarrahi A, Chakraborty A, Bharti SJ, et al. Cancer care delivery challenges amidst coronavirus disease - 19 (COVID-19) outbreak: Specific precautions for cancer patients and cancer care providers to prevent spread. Asian Pac J Cancer Prev 2020;21:569-73.
11. COVID 19 and Cancer, Supporting oncology professionals. Available from: https://www.esmo.org/newsroom/covid-19-andcancer. [Last accessed on 2020 Apr 02].

12. Hanna TP, Evans GA, Booth CM. Cancer, COVID-19 and the precautionary principle: Prioritizing treatment during a global pandemic. Nat Rev Clin Oncol 2020;17:268-70.

13. ASCO COVID 19 Provider and Practice Information. Available from: https://www.asco.org/asco-coronavirus-information/ provider-practice-preparedness-covid-19. [Last accessed on 2020 Apr 03].

14. Tsang J, Bajpai J. Novel coronavirus infection - Knowns and unknowns with particular reference to oncology - Combating against COVID-19 with "COVID". Indian J Med Paediatr Oncol [Internet] Available from: http://www.ijmpo.org/preprintarticle. asp?id=281591. [Last cited on 2020 Jun 05].

15. Mailankody S, Bajpai J. Intelligent adaptation to the changing surroundings amidst the COVID-19 pandemic for sarcomas and melanomas. Cancer Res Stat Treat 2020;3 Suppl S1:110-4.

16. Bartlett DL, Howe JR, Chang G, Crago A, Hogg M, Karakousis G, et al. Management of cancer surgery cases during the COVID-19 pandemic: Considerations. Ann Surg Oncol 2020;27:1717-20.

17. ACS. COVID-19: Guidance for Triage of Non-Emergent Surgical Procedures. Available from: https://www.facs.org/covid-19/ clinical-guidance/triage. [Last accessed on 2020 Apr 11].

18. ESMO Guidelines: Cancer Patient Management during The Covid-19 Pandemic. Available from: https://www.esmo.org/ guidelines/cancer-patient-management-during-the-covid-19pandemic. [Last accessed on 2020 May 27].

19. Yuen E, Fote G, Horwich P, Nguyen SA, Patel R, Davies J, et al. Head and neck cancer care in the COVID-19 pandemic: A brief update. Oral Oncol 2020;105:104738.

20. ICMR Strategy for COVID-19 Testing in India. Available from: https://main.icmr.nic.in/sites/default/files/upload_documents/ Testing_Strategy_v5_18052020.pdf. [Last accessed on 2020 May 27].

21. Al-Muharraqi MA. Testing recommendation for COVID-19 (SARS-CoV-2) in patients planned for surgery - Continuing the service and 'suppressing' the pandemic. Br J Oral Maxillofac Surg 2020. pii: S0266-4356(20)30164-9.

22. Economic Times: Covid 19: Private Hospitals use 'other' Clause to Test all Patients. Available from: https://economictimes. indiatimes.com/news/politics-and-nation/pvt-facilitiesuse-other-clause-to-test-all-patients/articleshow/75395750. cms?utm_source $=$ contentofinterest\&utm_medium $=$ text\&utm campaign $=$ cppst. [Last accessed on 2020 May 27].

23. ASTRO. COVID-19 Recommendations and Information. Available from: https://www.astro.org/Daily-Practice/COVID-19Recommendations-and-Information/Summary. [Last accessed on 2020 Apr 11].

24. Devadas SK, Banavali S. Retrospective analysis of outcomes of patients with relapsed, refractory and metastatic sarcomas who have received metronomic chemotherapy. Gulf J Oncolog 2019;1:22-8.

25. Kumar K, Radhakrishnan V, Dhanushkodi M, Kalaiyarasi JP, Mehra N, Kumar AR, Selvarajan G, Ganesan TS, Sagar TG. Oral etoposide and cyclophosphamide: A low-cost palliative metronomic chemotherapy in advanced pediatric cancers. Cancer Res Stat Treat 2020;3:64-8

26. Senerchia AA, Macedo CR, Ferman S, Scopinaro M, Cacciavillano W, Boldrini E, et al. Results of a randomized, prospective clinical trial evaluating metronomic chemotherapy in nonmetastatic patients with high-grade, operable osteosarcomas 
of the extremities: A report from the Latin American Group of Osteosarcoma Treatment. Cancer 2017;123:1003-10.

27. Raciborska A, Bilska K. Sorafenib in patients with progressed and refractory bone tumors. Med Oncol 2018;35:126.

28. Cotterill SJ, Ahrens S, Paulussen M, Jürgens HF, Voûte PA, Gadner H, et al. Prognostic factors in Ewing's tumor of bone: Analysis of 975 patients from the European Intergroup Cooperative Ewing's Sarcoma Study Group. J Clin Oncol 2000;18:3108-14.

29. Khanna N, Pandey A, Bajpai J. Metastatic Ewing's sarcoma: Revisiting the "Evidence on the Fence". Indian J Med Paediatr Oncol 2017;38:173-81.

30. Ladenstein R, Pötschger U, Le Deley MC, Whelan J, Paulussen M, Oberlin O, et al. Primary disseminated multifocal Ewing sarcoma: Results of the Euro-EWING 99 trial. J Clin Oncol 2010;28:3284-91.

31. Bajpai J, Chandrasekharan A, Talreja V, Simha V, Chandrakanth MV, Rekhi B, et al. Outcomes in non-metastatic treatment naive extremity osteosarcoma patients treated with a novel non-high dosemethotrexate-based, dose-dense combination chemotherapy regimen 'OGS-12'. Eur J Cancer 2017;85:49-58.

32. Marina NM, Smeland S, Bielack SS, Bernstein M, Jovic G, Krailo MD, et al. Comparison of MAPIE versus MAP in patients with a poor response to preoperative chemotherapy for newly diagnosed high-grade osteosarcoma (EURAMOS-1): An openlabel, international, randomised controlled trial. Lancet Oncol 2016;17:1396-408.

33. Bajpai J, Chandrasekharan A, Simha V, Mandal T, Shah K, Hingmare $\mathrm{S}$, et al. Osteosarcoma journey over two decades in India: Small steps, big changes. Pediatr Blood Cancer 2019;66:e27877.

34. Bajpai J, Chandrasekharan A, Simha V, Talreja V, Karpe A, Pandey $\mathrm{N}$, et al. Outcomes in treatment-naïve patients with metastatic extremity osteosarcoma treated with OGS-12, a novel non-highdose methotrexate-based, dose-dense combination chemotherapy, in a tertiary care cancer center. J Glob Oncol 2018;4:1-10.

35. Bajpai J, Puri A, Shah K, Susan D, Jambhekar N, Rekhi B, et al. Chemotherapy compliance in patients with osteosarcoma. Pediatr Blood Cancer 2013;60:41-4.

36. Turkar S. Current treatment landscape and emerging management options for extremity sarcoma. Cancer Res Stat Treat 2018;1:121-38.

37. Bajpai J, Susan D. Adjuvant chemotherapy in soft tissue
sarcomas...Conflicts, consensus, and controversies. South Asian J Cancer 2016;5:15-9.

38. Park KH, Choi YJ, Kim KW, Ro KH, Kang CH, Song SH, et al. Combination chemotherapy with methotrexate and vinblastine for surgically unresectable, aggressive fibromatosis. Jpn J Clin Oncol 2016;46:845-9.

39. NCCN Guidelines for Melanoma Treatment during COVID 19. Available from: https://www.nccn.org/covid-19/pdf/Melanoma. pdf. [Last accessed on 2020 Apr 03].

40. Ministry of Health and Family Welfare resources. Available from: https://www.mohfw.gov.in/. [Last accessed on 2020 Apr 05].

41. Ministry of Health and Family Welfare. Novel Coronavirus Disease 2019 (COVID-19): Guidelines on Rational use of Personal Protective Equipment. Available from: https://www.mohfw.gov. in/pdf/GuidelinesonrationaluseofPersonalProtectiveEquipment. pdf. [Last accessed on 2020 Apr 11].

42. Times of India. COVID-19: How safe are our doctors. Available from: https://timesofindia.indiatimes.com/india/covid-19-howsafe-are-our-doctors/articleshow/74924901.cms. [Last accessed on 2020 Apr 11].

This is an open access journal, and articles are distributed under the terms of the Creative Commons Attribution-NonCommercial-ShareAlike 4.0 License, which allows others to remix, tweak, and build upon the work non-commercially, as long as appropriate credit is given and the new creations are licensed under the identical terms.

For reprints contact: WKHLRPMedknow_reprints@wolterskluwer.com

\begin{tabular}{|l|l|}
\hline \multicolumn{2}{|c|}{ Access this article online } \\
\hline Quick Response Code: & Website: \\
& www.ijmpo.org \\
\cline { 2 - 2 } & DOI: \\
\hline
\end{tabular}

How to cite this article: Mailankody S, Bajpai J. How I Treat sarcomas during COVID-19 pandemic: Caught between the devil and the deep sea! Indian J Med Paediatr Oncol 2020;41:299-302. 